\title{
Aerodynamic levitation: an approach to microgravity
}

\author{
Benoit Glorieux ${ }^{1}$, Marie-Louise Saboungi ${ }^{1}$, Francis Millot ${ }^{2}$, John Enderby ${ }^{3}$, \\ and Jean-Claude Rifflet ${ }^{2}$ \\ ' Materials Science Division, Argonne National Laboratory, \\ 9700 South Cass Avenue, Argonne, IL 60439, USA \\ 2 Centre de Recherche sur les Materiaux a Hautes Temperatures, CNRS, \\ 1D Avenue de la Recherche Scientifique, 45071, Orleans, France \\ ${ }^{3}$ H H Wills Physics Laboratory, Tyndall Avenue, Bristol, BS8 1TL, UK
}

To be presented at the Space Technology and Applications International forum, Albuquerque, NM, February 11-15, 2001, Sponsored by the University of New Mexico

This work was supported by the U.S. Department of Energy, Office of Science, under contract \#W-31-109-ENG-38 and by the financial support of the French agency CNES

\begin{abstract}
The submitted manuscript has been created by the University of Chicago as Operator of Argonne National Laboratory ("Argonne") under Contract No. W-31-109-ENG-38 with the U.S. Department of Energy. The U.S. Government retains for itself, and others acting on its behalf, a paid-up, nonexclusive, irrevocable worldwide license in said article to reproduce, prepare derivative works, distribute copies to the public, and perform publicly and display publicly, by or on behalf of the Government.
\end{abstract}




\section{DISCLAIMER}

This report was prepared as an account of work sponsored by an agency of the United States Government. Neither the United States Government nor any agency thereof, nor any of their employees, make any warranty, express or implied, or assumes any legal liability or responsibility for the accuracy, completeness, or usefulness of any information, apparatus, product, or process disclosed, or represents that its use would not infringe privately owned rights. Reference herein to any specific commercial product, process, or service by trade name, trademark, manufacturer, or otherwise does not necessarily constitute or imply its endorsement, recommendation, or favoring by the United States Government or any agency thereof. The views and opinions of authors expressed herein do not necessarily state or reflect those of the United States Government or any agency thereof. 


\section{DISCLAIMER}

Portions of this document may be illegible in electronic image products. Images are produced from the best available original document. 


\title{
Aerodynamic levitation: an approach to microgravity
}

\author{
Benoit Glorieux ${ }^{1}$, Marie-Louise Saboungi ${ }^{1}$, Francis Millot ${ }^{2}$, John Enderby ${ }^{3}$ and \\ Jean-Claude Rifflet ${ }^{2}$
}

\author{
'Materials Science Division, Argonne National Laboratory, 9700 South Cass Avenue, Argonne, IL 60439, USA. \\ ${ }^{2}$ Centre de Recherche sur les Materiaux a Hautes Temperatures, CNRS, ID Avenue de la Recherche Scientifique, \\ 45071, Orleans, France. \\ ${ }^{3} \mathrm{H} H$ Wills Physics Laboratory, Tyndall Avenue, Bristol, BS8 ITL, UK \\ (630)252-9760,glorieux@anl.gov
}

\begin{abstract}
Measurements of the thermophysical and structural properties of liquid materials at high temperature have undergone considerable development in the past few years. Following improvements in electromagnetic levitation, aerodynamic levitation associated with laser heating has shown promise for assessing properties of different molten materials (metals, oxides, and semiconductors), preserving sample purity over a wide range of temperatures and under different gas environments. The density, surface tension and viscosity are measured with a high-speed video camera and an image analysis system. Results on nickel and alumina show that small droplets can be considered in the first approximation to be under microgravity conditions. Using a non-invasive contactless technique recently developed to measure electrical conductivity, results have been extended to variety of materials ranging from liquid metals and liquid semiconductors to ionically conducting materials. The advantage of this technique is the feasibility of monitoring changes in transport occuring during phase transitions and in deeply undercooled states.
\end{abstract}

\section{IINTRODUCTION}

The understanding of liquid phase thermophysical properties is still subject to some questions. Electromagnetic levitation has shown both the possiblity of and the need for containerless melting to provide uncontaminated conditions.

A recent aerodynamic levitation set-up (Coutures, 1986) has been developed to melt different oxides. Using a specific chamber (Millot 2000; Weber, 1991), this technique is, for the past few years, available to study various kinds of material, including metals, semi-conductors and insulators. To investigate properties of the melt, contactless tools are in conjunction with to the levitation set-up. Pyrometers are applied to measure the temperature, and optical methods and image analysis are used to measure density, surface tension and viscosity. A resonant RF coil allows the measurement of conductivity.

This paper reports on the different aerodynamic levitation set-up, the basic theory involved for the different properties and some examples of results determined by these techniques.

\section{AERODYNAMIC LEVITATION}

This technique (Nordine, 1982), in comparison with the other levitation (electromagnetic, electrostatics, accoustic) methods is technically the simplest way to maintain a sample without any contact with a crucible. 
The principle is based on the flow of a gas through a special nozzle where is located a few millimeter diameter sample. By adjusting the delivery of gas, the droplet is stabilized in a potential energy minimum (Paradis, 1996) over the divergent wall of the nozzle.

The device used to determine density, surface tension and viscosity is shown schematically in figure 1 . In order to obtain a stable liquid state, a $\mathrm{CO}_{2}$ laser $(\lambda=10.6 \mu \mathrm{m})$ heats the levitated sample from the top, and the optically polished surface of the divergent aluminum nozzle reflects the external part of the laser beam on the side of the droplet. Recently (Glorieux, 1999), new improvements were done to reduce the gradient temperature by heating the sample from the top and bottom using a second $\mathrm{CO}_{2}$ laser and a special angle of the nozzle cone wich focuses the laser beam on the bottom of the droplet. The apparent temperature is deduced from the voltage signal $\mathrm{V}$ of a pyrometer.

$$
\mathrm{T}=\frac{\mathrm{C}_{2}}{\lambda \cdot \ln \left(\frac{\mathrm{k}+\mathrm{V}}{\mathrm{V}}\right)},
$$

where $C_{2}$ is Planck's second radiation constant equal to $1.438810^{-2} \mathrm{~m} \cdot \mathrm{K}, \lambda$ is the pyrometer wavelength and $k$ is a constant deduced from the apparent solidification temperature of the sample.

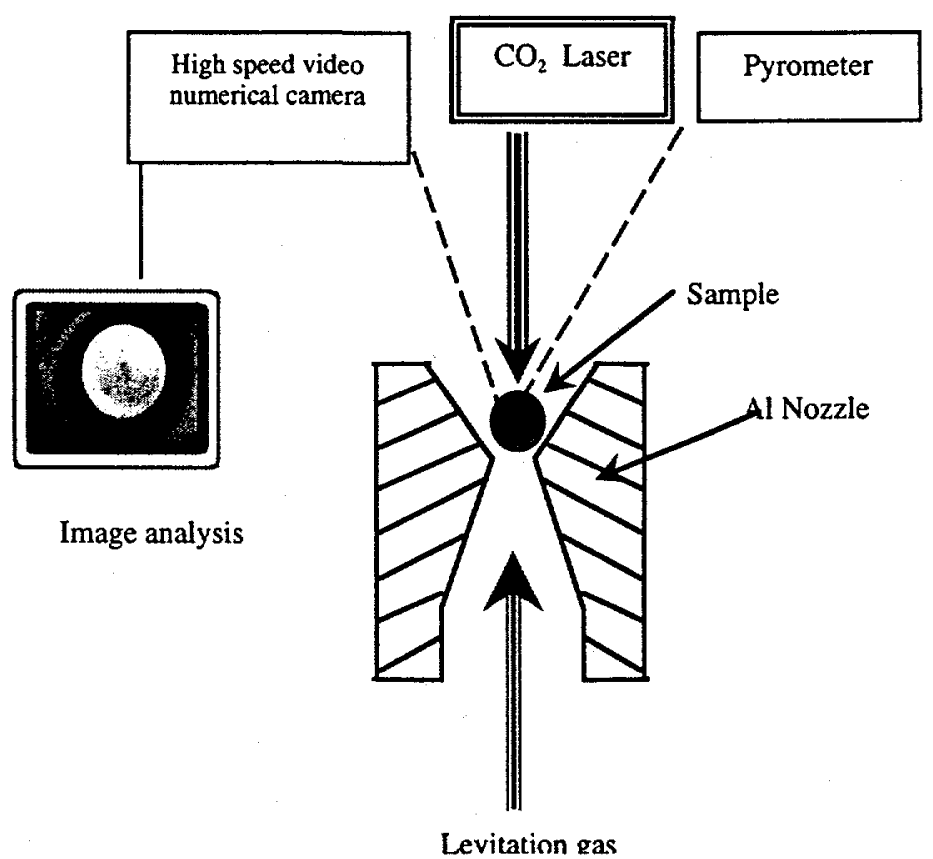

FIGURE 1. Aerodynamic Levitation Set-Up with Aluminum Nozzle.

The top of the alumina droplet is observed with a numerical high speed camera recording from 1 to 1000 images per second with a $512 * 384$ pixel image area. A powerful image analysis software (Visilog) makes it possible to calculate the geometrical parameter of the levitated liquid (surface central point, radius, diameter and area).

In order to measure the conductivity of the sample, some modifications have to be made on the levitation set-up (fig. 2) (Weber, 1991). The first restriction is to use boron nitride as the material for the nozzle due to its insulating characteristics. The second is to reduce the length of the cone to approach the measurement device as close as possible to the sample. These modifications imply poorer stability and temperature homogeneity. The coil consists of approximately 20 turns around a ferrite toroid with a $6 \mathrm{~mm}$ gap removed to place the sample in. The coil is attached to a water jacket, and the inside wall of the ferrite is shielded by an aluminum nitride sheet connected to the 
water cooling. The lead from the coil is fed into an LCR meter that measure the change in inductance $L$, resistance $R$ and quality factor $Q$, in order to deduce the permeability and the conductivity of the sample

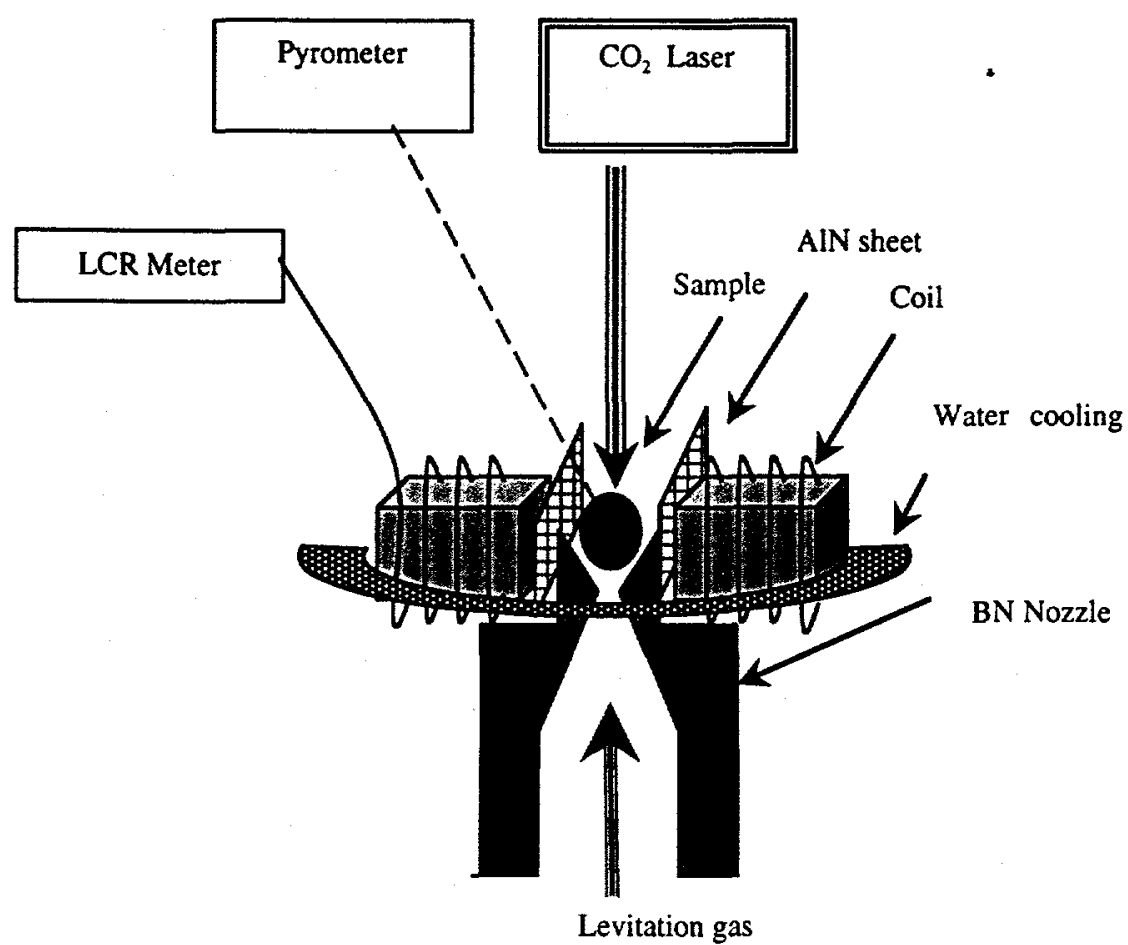

FIGURE 2. Aerodynamic Levitation Set-Up with Boron Nitride Nozzle.

\section{THERMOPHYSICAL PROPERTIES}

\section{Density}

The mass $M$ of the sample is determined before and after the levitation experiment, and only experiments with negligible weight losses (due to evaporation, thermal schock) are used. To determine the volume $V$, the sample is heated to high temperature and then the laser is turned off. The video camera records the image during the free cooling. Because only the top surface $\mathrm{S}$ can be viewed by the camera, an assumption about the shape is necessary. For small samples, the shape is nearby spherical (Glorieux, 1999).

$$
\mathrm{V}=\frac{4}{3 * \sqrt{\pi}}(\mathrm{S})^{\frac{3}{2}}
$$

An adjustment of this relation was made (Glorieux, 2000; Hansen, 1991) to increase the accuracy of the method.

\section{Surface tension}

The surface tension $\gamma$ can be measured by studying the oscillation of a stable droplet. The time evolution of the radius of the drop is defined by (Raileigh, 1879): 


$$
R(t)=R_{0}\left(1+\varepsilon \cos (\omega t) e^{-\frac{t}{\tau}}\right)
$$

where $R_{0}$ is the initial radius of the spherical sample, $\varepsilon$ the oscillation amplitude, $\omega$ the frequency and $\tau$ the damping constant. The frequency of the oscillation is related to the surface tension by Chandrasekar, (1959):

$$
\gamma=\frac{3 \mathrm{M} \omega^{2}}{32 \pi} .
$$

The frequency is obtained by a Fast Fourier Transform of the geometrical parameter of the sample measured by image analysis.

In aerodynamic levitation, a small shifting of the frequency can appears as a function of the rotation axis, contrary to electromagnetic levitation (Egry, 1999) where translation movements are more important. But a complicated splitting of the frequency is observed, due to gravity, the rotation and the precession of the sample, which complicates the analysis of the data. Recent work (Millot, 2000) provides an excellent interpretation of the FFT signal.

\section{Viscosity}

Viscosity is one of the most difficult properties to measure with contactless techniques. Only electromagnetic levitation experiments in microgravity (Egry, 1993) have been successful. Some results have been published using electrostatic levitation (Rhim, 1997).

The viscosity $\eta$ is related to the damping coefficient $\tau$ of the oscillation (3) using a relation defined by Lamb (1932):

$$
\eta=\frac{3 \mathrm{M}}{20 \pi \mathrm{R}_{\mathrm{o}} \tau} \text {. }
$$

Experiments using an external pseudo-instantaneous excitation were not successful in measuring the $\tau$ parameter. Only the width of the oscillation peak could be used to approximate this coefficient (Glorieux, 2000), and the relation (5) should certainly be improved, taking account of gravity and the convective transport.

\section{Electrical conductivity}

The conductivity $\sigma$ of a sample is deduced from the change of inductance $L$ and eddy losses coming from the insertion of the sample into the coil. The complex susceptibility can be written by (Landau, 1984) :

$$
\alpha=\alpha^{\prime}+i \alpha^{\prime \prime},
$$

where the real part and the imaginary part are (Enderby, 1997):

$$
\begin{gathered}
\alpha^{\prime}=\frac{\Delta \mathrm{L}}{\mathrm{L}} \frac{1}{\theta}, \\
\alpha^{\prime \prime}=-\frac{\Delta \mathrm{R}}{\omega . \mathrm{L}} \frac{1}{\theta} .
\end{gathered}
$$


Where the filling factor $\theta$ is a purely geometrical quantity, $R$ and $Q$ is the resistance and $\omega$ is the frequency of the magnetic field. The classical skin depth $\delta$ is given by:

$$
\delta=\sqrt{\frac{2}{\omega \sigma \mu_{0}}} .
$$

Some approximations can be done for poor conductors $\left(\delta>>R_{0}\right)$ and for good conductors $\left(\delta<<R_{0}\right)$ :

$$
\begin{aligned}
& \delta<<\mathrm{R}_{0} \rightarrow \alpha^{\prime}=\left(\frac{3}{2}\right)\left(1-\frac{3 \delta}{2 \mathrm{R}_{0}}\right) \quad \alpha^{\prime \prime}=\left(\frac{9}{4}\right)\left(\frac{\delta}{\mathrm{R}_{0}}\right), \\
& \delta>>\mathrm{R}_{0} \rightarrow \alpha^{\prime}=\left(\frac{4 \pi}{105}\right)\left(\frac{\mathrm{R}_{0}}{\delta}\right)^{4} \quad \alpha^{\prime \prime}=\left(\frac{1}{5}\right)\left(\frac{\mathrm{R}_{0}}{\delta}\right)^{2} .
\end{aligned}
$$

When both $\alpha^{\prime}$ and $\alpha^{\prime \prime}$ are measured, the filling factor does not need to be known, the above equations are solved iteratively to derive $\delta$, wich yields to the electrical conductivity.

\section{RESULTS}

The major part of the results come from the study of liquid alumina ( $\mathrm{mp}=2327 \mathrm{~K}$ ), motivated by the need of exact knowledge of these properties to understand the state of the liquid alumina in the French Ariane $V$ booster following the combustion of aluminum powder. Also alumina is often used for initial experiments in aerodynamic levitation due to its ease of levitation. Futher experiments on metals and semi-conductors are actually in preparation.

\section{Density}

The density of liquid alumina (Glorieux, 2000) was determined from the undercooled state to $3100 \mathrm{~K}$ for droplets weighing 14 to $150 \mathrm{mg}$ in oxygen, argon and $\mathrm{Ar} / \mathrm{H}_{2}$ atmosphere .

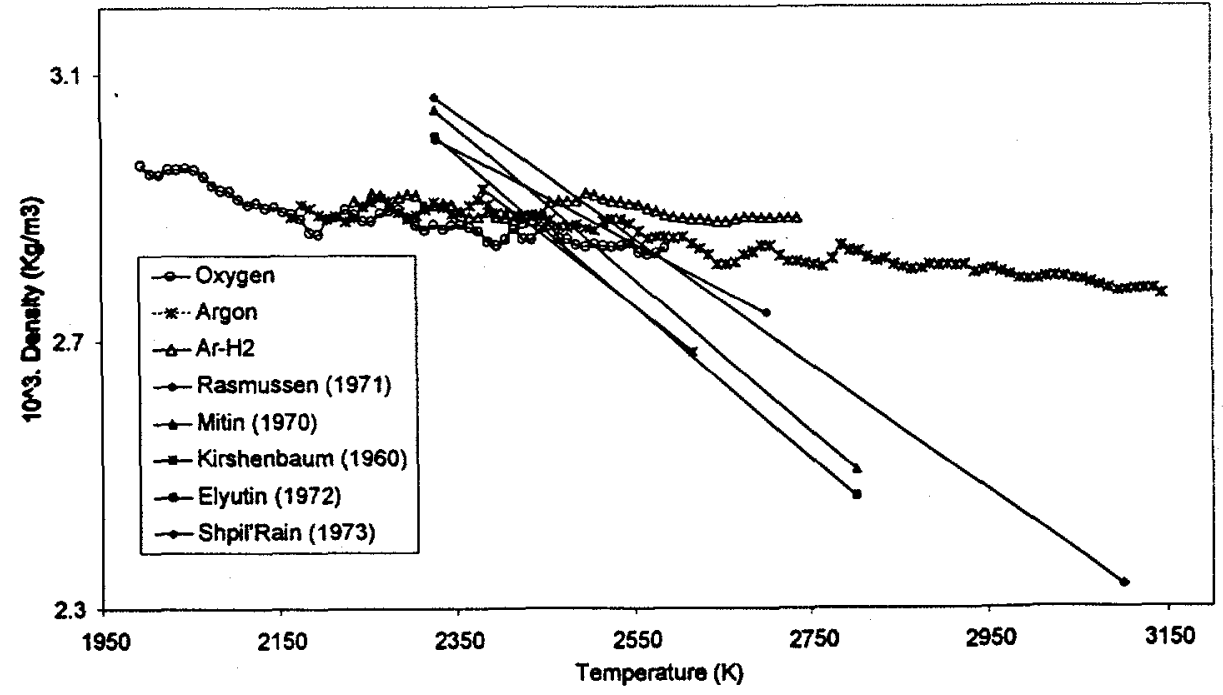

FIGURE 3. Density of Liquid Alumina. 
The three data sets yield to a common density of:

$$
\rho_{\mathrm{Al}_{2} \mathrm{O}_{3}}\left(\mathrm{~T}_{\mathrm{K}}\right)=2870 *\left(1-\chi_{\rho}\left(\mathrm{T}_{\mathrm{K}}-2500\right)\right)\left(\mathrm{kg} / \mathrm{m}^{3}\right) \text {, }
$$

where the thermal expansion coefficient $\chi_{p}$ is $3.3210^{-5} \mathrm{~K}^{-1}$ at $2500 \mathrm{~K}$

At the melting point, the results are in good agreement with published data, but the thermal expansion coefficient is smaller than those deduced from techniques involving contact between the sample and crucible.

\section{Surface tension}

Several experiments were done with nickel droplets in a reducing environment around $2180 \mathrm{~K}$. The weight of the sample were 53,77, 96 and $134 \mathrm{mg}$. The oscillation of the geometrical parameter of the levitated nickel droplets were measured and fitted by the theoretical expression for the oscillation at specific rotation and precession velocities.

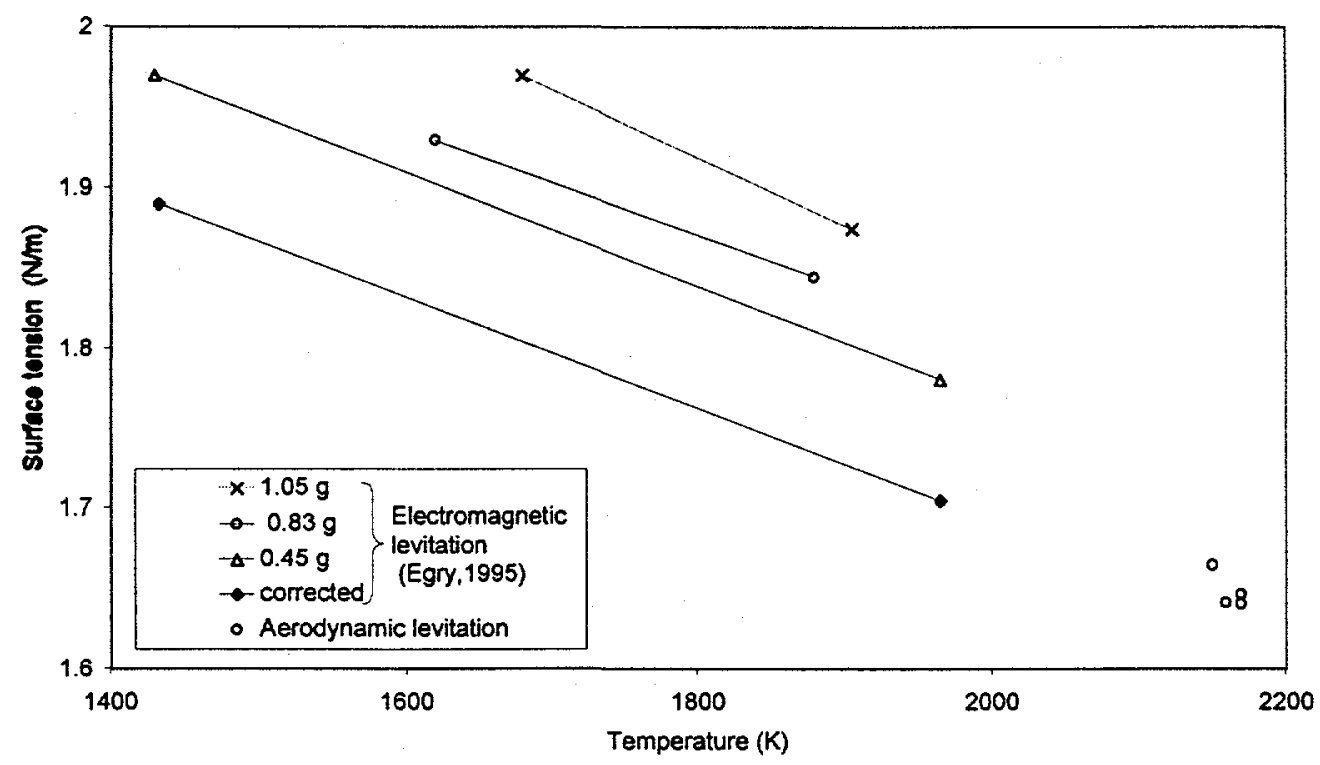

FIGURE 4. Surface Tension of Liquid Nickel.

In contrast to the ground electromagnetic measurements of Egry and al (1995), the surface tension deduced from aerodynamic levitation does not show any effect of the weight of the sample. The results are in agreement with the corrected results for the electromagnetic measurements.

\section{Viscosity}

At this time, only results from liquid alumina are available, approximated from the width of oscillation peak (Glorieux, 2000). The accuracy of result is about $50 \%$, due to the difficulties in measuring the width, especially below $2700 \mathrm{~K}$ and for big droplet, the oscillation peaks are not well defined. The alumina viscosity is about 10 $\mathrm{mPa}$.s at $2700 \mathrm{~K}$ and $6 \mathrm{mPa}$,s at $3300 \mathrm{~K}$. In contrast to previous measurements involving contact techniques, we collected data only from 2700 to $3250 \mathrm{~K}$. Our results follows the extrapolation of some of the published data, but a differentiation between the different classical models for the temperature dependence of the viscosity is not possible. 


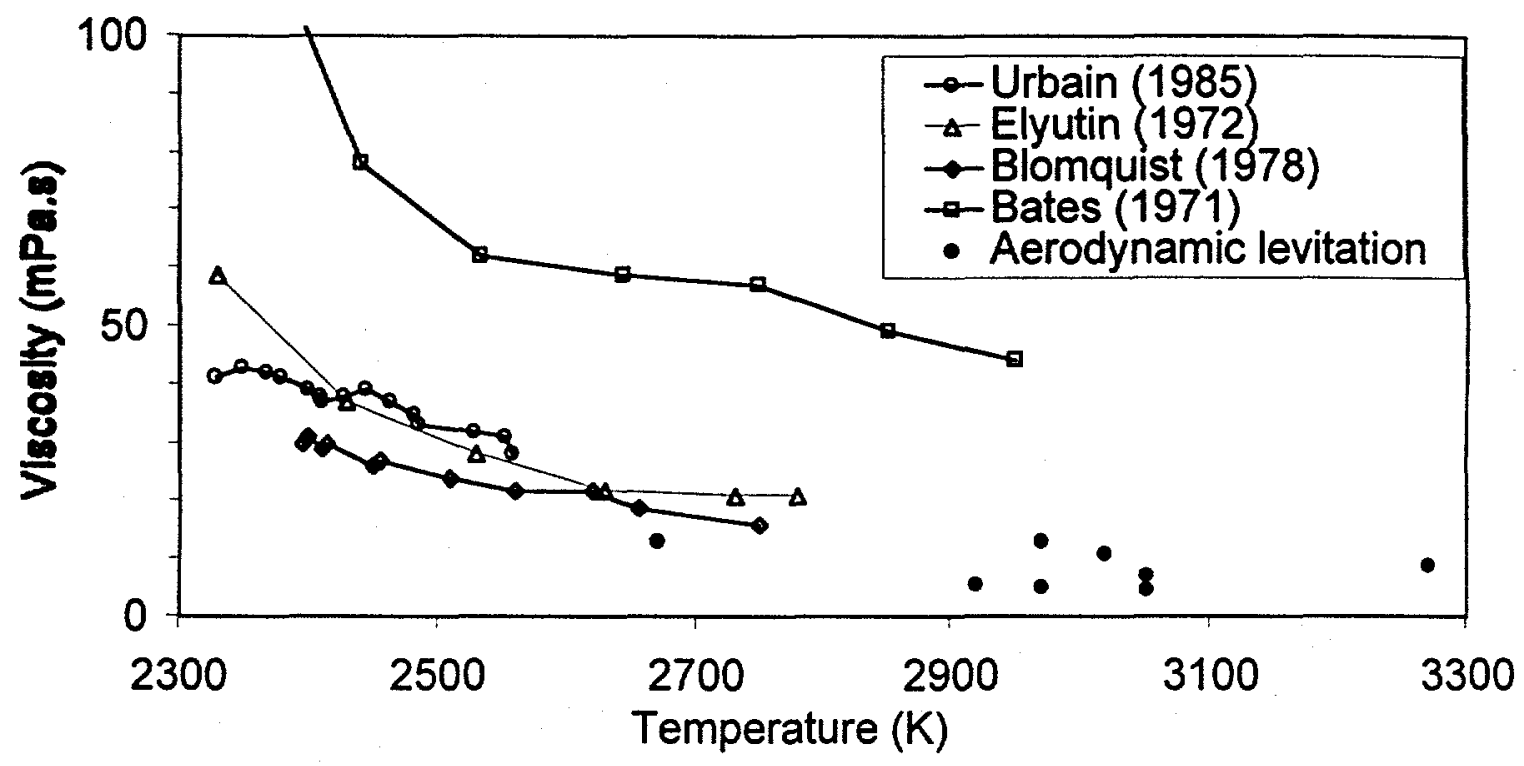

FIGURE 5. Viscosity of Liquid Alumina.

\section{Electrical conductivity}

Using the fact that alumina is an insulator in the solid state, changes in $\mathrm{Q}$ and $\mathrm{L}$ were measured between hot solid alumina (at about $1900 \mathrm{~K}$ ) and molten sample (from $2200 \mathrm{~K}$ to $3100 \mathrm{~K}$ ). During each experiment, the inductance has not to change between hot solid and liquid. For insulator, the change in $\mathrm{L}$ is only due to the increase of temperature.

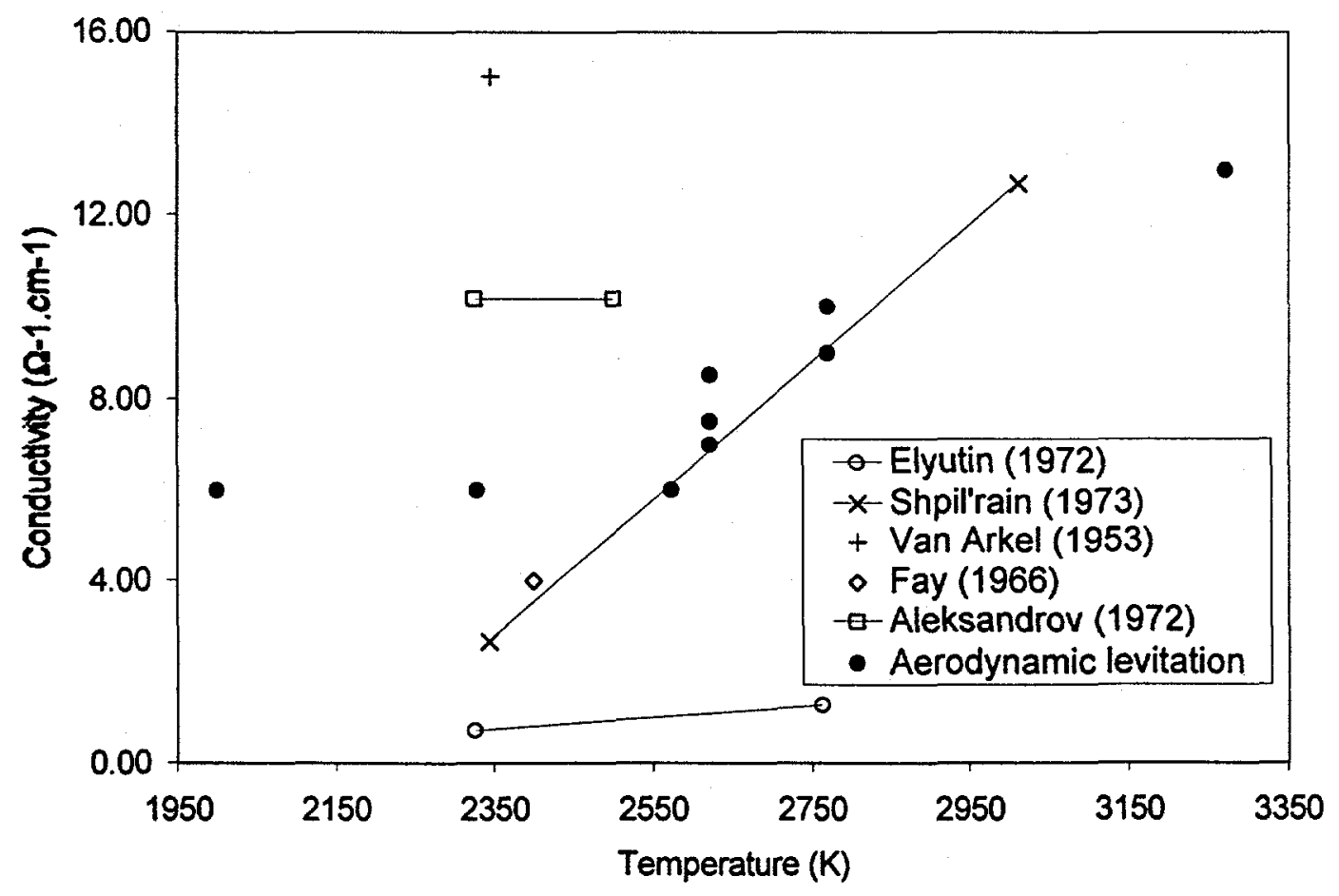

FIGURE 6. Conductivity of Liquid Alumina. 
Measurements were done in oxygen and argon environments. The previous measurements showed a big spread in value. The values obtained in this work are from $6 \Omega^{-1} . \mathrm{cm}^{-1}$ at $2000 \mathrm{~K}$ and $13 \Omega^{-1} . \mathrm{cm}^{-1}$ at $3300 \mathrm{~K}$. The accuracy of the results is about $15 \%$

\section{DISCUSSION AND CONCLUSION}

Contactless measurements with aerodynamic levitation can provide high-quality data on thermophysical properties of molten and undercooled materials.

Data for density and surface tension, especially for oxides, at the melting point, are similar to those obtained from contact techniques. The temperature dependence, however, is significantly smaller. This means that the samples contained in crucibles are contaminated, with every kind of crucible material, and the literature data have to be treated with caution.

For small droplets ( $<120 \mathrm{mg}$ in the case of alumina), the shape of the sample is approximately spherical, and the gravity field does not produce an important shift in oscillation frequency. The sample can be considered, in the first approximation, to be under microgravity conditions. But gravity, in combination with rotation and precession, does lead to a complicated splitting of oscillation frequency. The treatment of the data is not easy, but a study of different geometrical parameters (Millot, 2000; Sauerland, 1993) can provide an accurate result.

The coherence of the results for surface tension and density is display by the similar temperature coefficients (Glorieux, 2000), due to the same proportionality of density and surface tension to interatomic distance.

Viscosity is the most difficult property to assess. An approximation can made using the width of the oscillation peak for oxides, or a relation between surface tension and viscosity for pure metals (Egry, 1993). Different excitation techniques were tried, but the complex splittinf of the oscillation, the gravity field, rotation and precession makes it difficult to interpret the signals. There is a huge need for viscosity data from the industrial and scientific communities, but a major development of the technique is necessary before this property can be determined with an acceptable accuracy.

The difficult part of the conductivity measurements is maintaining the coil at a constant temperature. Improvements have been made in measuring conductivity in a wide variety of materials (metals, insulators, semiconductors) in the liquid and undercooled states. For liquid semiconductors, a first order phase transition is expected in the deeply undercooled. A confirmation of it will lead to microgravity experiments to investigate the undercooled liquid by eliminating convective transport in the droplet, then reducing temperature gradient, to describe kinetics of this liquid-liquid transformation, in correlation with structural measurements.

\section{ACKNOWLEDGMENTS}

This work was supported by the financial support of the French agency CNES (Centre National d'Etude Spatiales and by the U.S. Departement of Energy, Office of Science, under contract W-31-109-ENG-38

\section{REFERENCES}

Aleksandrov, V.I., Osiko, V.V. and Tatarintsev, V.M., Izv. Akad. Nauk SSSR Neorg. Mater. 8, 956-962 (1972).

Bates, J.L., Mc Neilly, C.E. and Rasmussen, J.J., Ceramics in severe environments, Mat. Res., New York, Ed. W.W. Kriegel and H. Palmour III. Plenum press, 1971, Vol. 5.

Bloomquist R.A., Fink J.K. and Leibowitz L., "Viscosity of molten alumina", Ceram. Bull., 5, $522-524$ (1978).

Chandrasekar, S., "The oscillations of a viscous globe", Proc. Lond. Math. Soc., 9(3), 141-149 (1959).

Coutures, J.P., Rifflet, J.C., Billard, D.and Coutures, J., "Contactless Treatments of Liquids in a Large Temperature Range by an Aerodynamic Levitation Device and Laser Heating" in $6^{\text {th }}$ European Symposium on materials Science Under Microgravity Condition, ESA SP-256 European Space Agency, 1987, pp. 427-430

Egry, I., "Structure and properties of levitated liquid metals", J. of Non-Cryst. Sol. 250-252, 63-67 (1999). 
Egry, I.and Feuerbacher, B., "Thermophysical properties of undercooled liquid metals", Microg. Sci. and Tech. 6(2), 78-82 1993.

Egry, I., Lohofer, G. and Jacobs, G., "Surface tension of liquid metals: Results from measurements on ground and in space". Phys. Rev. Let. 75, 22-28 (1995).

Egry, I., 'On the relation between surface tension and viscosity for liquid metals", Scrip. met. and mat. 28(10), 1273-1275 (1993).

Elyutin, V.P., Mitin, B.C. and Nagibin, Y.A., "Proprietes de l'alumine liquide" Fiz Aerodispersnykh sist. 7, 104-109 (1972).

Enderby, J., Ansell, S., Krishnan, S., Price, D. L. and Saboungi, M. L., "The electrical conductivity of levitated liquids", Appl. Phys. Let. 71(1), 116-118 (1997).

Fay, H., J. Phys. Chem. 70, 890-893 (1966).

Glorieux, B., Rifflet, J.C. and Millot F., "Density of superheated and undercooled liquid alumina by a contactless method", Int. J. of Thermophys. 20(4), 1085-1094 (1999).

Glorieux B., " Mesure de la densite, de la tension superficielle et de la viscosite de l'alumine liquide en fonction $d$ ela temperature et de l'environnement" Thesis, Universite d'Orleans, april 2000.

Hansen, F.K. and Rødsrud G., "Surface tension by pendant drop. Fast standard instument using computer image analysis" J. Colloid Interface Sci. 141(1), 1-12 (1991).

Kirshenbaum, A.D. and Cahill J.A., "Density of liquid alumina", J. Inorg. Nucl. Chem. , 14, 1960, 283-287.

Weber, J.K.R., Krishnan, S. and Schiffman, R.A. "Optical and thermodynamic property measurements of liquid metals and alloys", Adv. in space research, 11(7), 43-52 (1991).

Lamb, H., Hydrodynamis, Cambridge, Camb. Univ. Press, 1932.

Landau, L.D., Lifshitz, E.M. and Pitaevskii L.P., Electrodynamics of Continuous Media, Oxford, Pergamon Press, 1984.

Lord Rayleigh, On the capillary phenmena jets, London, Proc. Roy. Soc., 1879, Vol. 29, pp 71.

Millot, F, Rifflet, J.C., Wille, G., Sarou Kanian, V. and Glorieux B., "Surface tension of high temperature liquids with an aerodynamic levitation set up", 2000, to appear.

Mitin, B.S. and Nagibin, Y.A., Rus. J. of Phys. Chem. 44, 741-742, (1970).

Nordine. P.C., Atkins. R.M., "Aerodynamic levitation of laser-heated solids in gas jets", Rev. of Sci. Inst. 53(9), $1982,1456-64$.

Paradis P.F., "Fusion et vitrification sans contact par piégeage aérodynamique et par laser de sphères diélectriques au sol et en microgravité Thesis, University of Montreal, 1996.

Rasmussen, J.J. and Nelson R.P., "Surface Tension and Density of Molten $\mathrm{Al}_{2} \mathrm{O}_{3}$ ”, J. Amer. Ceram. Soc. 54, 1971, 398-401.

Rhim, W.K., Chung, S.K., Rulison, A.J. and Spjut, R.E., "Measurement of thermophysical properties of molten silicon by a high temperature electrostatic levitator" Int. J. of Thermophys., 18(2), 1997, 459-469.

Sauerland, S., Lohofer, G. and Egry, I., "Surface tension measurements on levitated aspherical liquid nickel drops". Thermochi. Acta., 218, 445-450 (1993).

Shpil'rain, E.E., Yakimovich, K.A. and Tsitsarkin, A.F., High Temp. High Press. 5, 191-198 (1973).

Urbain G., "Viscosite de l'alumine liquide", Rev. Int. Hautes Temp. Refract., Fr., 19, 55-57 (1982).

Van Arkel, A.E., Flood, E.A. and Bright N.F.H. "Conductivity of liquid alumina", Can. J. Chem. 31, 1009-1013 (1953). 